\title{
NUMERICAL ANALYSIS OF THE INFLUENCE OF IN-PLANE CONSTRAINTS ON THE CRACK TIP OPENING DISPLACEMENT FOR SEN(B) SPECIMENS UNDER PREDOMINANTLY PLANE STRAIN CONDITIONS
}

\author{
M. GRABA \\ Kielce University of Technology \\ Faculty of Mechatronics and Mechanical Engineering \\ Department of Manufacturing Engineering and Metrology \\ Al. 1000-lecia PP 7, 25-314 Kielce, POLAND \\ E-mail:mgraba@tu.kielce.pl
}

\begin{abstract}
This paper presents a numerical analysis of the relationship between in-plane constraints and the crack tip opening displacement (CTOD) for single-edge notched bend (SEN(B)) specimens under predominantly plane strain conditions. It provides details of the numerical model and discusses the influence of external load and inplane constraints on the CTOD. The work also reviews methods for determining the CTOD. The new formula proposed in this paper can be used to estimate the value of the coefficient $d_{n}$ as a function of the relative crack length, the strain hardening exponent and the yield strength $-d_{n}\left(n, \sigma_{0} / \mathrm{E}, a / W\right)$, with these parameters affecting the level of in-plane constraints. Some of the numerical results were approximated using simple mathematical formulae.
\end{abstract}

Key words: SEN(B), J-integral, CTOD, Q-stresses, fracture, FEM, coefficient $d_{n}$.

\section{Introduction}

The Hutchinson, Rice and Rosengren (HRR) solution published in 1968 [1, 2] was intended to describe stress fields near the crack tip in elastic-plastic materials. That approach, proposed nearly 50 years ago, has been extended by many researchers because of the imperfect description of stress fields [3]. The description of stress fields does not refer to the crack length, the width and thickness of a structural element (specimen) and the type of external load (including the load mode) [3]. These parameters affect the geometric constraints, i.e., the resistance offered by the material to plastic deformations [4]. In fracture mechanics, geometric constraints are divided into out-of-plane and in-plane constraints [4]. The former are related to the thickness of a structural element, which is responsible for the stress triaxiality around the crack tip [3, 4]. Examples include parameters $T_{z}$ and $\mathrm{Q}^{*}$ and the ratio of effective stresses to the yield strength [3]. In-plane constraints, on the other hand, are dependent on the specimen width, the crack length as well as the method of loading (bending or tension) [3]. Q-stresses defined by O'Dowd and Shih [7, 8] are a common measure of in-plane constraints; they are used not only to correct the distributions of stresses but also to create the fracture criteria [5,6]. Q-stresses are frequently calculated as the difference between the stresses responsible for crack tip opening displacements determined numerically and the stresses obtained from the HRR formula $[3,7,8]$

$$
Q=\frac{\left(\sigma_{\theta \theta}\right)_{F E M}-\left(\sigma_{\theta \theta}\right)_{H R R}}{\sigma_{0}} \quad \text { for } \quad \theta=0 \quad \text { and } \quad r=\frac{2.0 \cdot J}{\sigma_{0}}
$$


where $\left(\sigma_{\theta \theta}\right)_{F E M}$ is the numerical value of stresses, while $\left(\sigma_{\theta \theta}\right)_{H R R}$ is the value of stresses resulting from the HRR solution

$$
\sigma_{i j}=\sigma_{0}\left(\frac{J}{\alpha \sigma_{0} \varepsilon_{0} I_{n} r}\right)^{\frac{1}{1+n}} \widetilde{\sigma}_{i j}(\theta, n)
$$

where $i, j$ - components of the stress tensor, $J-J$-integral, $\sigma_{0}$-yield strength, $\varepsilon_{0}$ - strain corresponding to the yield strength, calculated as $\varepsilon_{0}=\sigma_{0} / \mathrm{E}, \mathrm{E}$ - Young's modulus, $n$ - exponent in the Ramberg-Osgood (RO) law, $\alpha$ - material constant in the RO law, $I_{n}$ - quantity dependent on the material through the exponent $n$, the method of loading and the specimen thickness, which defines whether plane stress or plane strain conditions are predominant $[1-3,9], \tilde{\sigma}_{i j}(\theta, n)$ - functions dependent on the material through the exponent $n$, the angle $\theta$ and on the specimen thickness, according to the dominance of the plane stress or plane strain state [1-3,9].

The investigations that followed showed that Q-stresses were a parameter that was sensitive to the geometry of a specimen (structural element), the crack length and the material characteristics (the exponent in the RO law and the yield strength). As mentioned above, the parameter was used to verify the fracture criteria as well as to relate the J-integral (i.e., the parameter controlling the stress field around the crack tip, considered to be the pulling force of the crack [4]) with another parameter of elastic-plastic fracture mechanics - the crack tip opening displacement $\delta_{T}$. O'Dowd and Shih showed that there existed a relationship between Q-stresses and the crack tip opening displacement [7, 8].

The crack tip opening displacement is a measure of plastic strains in the area near the crack tip. This is related to large plastic strains occurring in a material due to large external loads being a result of intensive growth and coalescence of voids inside the material in the area near the crack tip [4]. Wells [10] claimed that the crack length occurred when the crack tip opening displacement reached a critical value, which was a fundamental finding to determine an appropriate fracture criterion [3, 4]. In 1981, Shih [11] proposed a numerical procedure to determine the crack tip opening displacement (Fig.1a); he also related the J-integral with the crack tip opening displacement using the following formula

$$
\delta_{T}=d_{n} \frac{J}{\sigma_{0}}
$$

where $d_{n}$ is dependent on the parameters of the Ramberg-Osgood curve, the yield strength, Young's modulus and the distribution of stresses near the crack tip defined according to the HRR solution. The values of the parameter $d_{n}$ can be determined using the computer program described in [9]. Figure 1b is a graphical representation of the relationship between the function $d_{n}$ dependent on the yield strength $\sigma_{0}$ and the strain hardening exponent $n$ in the RO law.

It is evident that the value of the coefficient $d_{n}$ is strongly dependent on the degree of material strain hardening (expressed by the strain hardening exponent $n$ ) and weakly dependent on the ratio of the yield strength to Young's modulus (Fig.1b). First, Shih [11] proposed that the values of the coefficient $d_{n}$ be determined only on the basis of functions with tilde, characteristic of the HRR solution [9]. Then, however, after a series of numerical analyses, he indicated that the coefficient $d_{n}$ should be strongly dependent on the exponent $n$ and strains corresponding to the yield strength $\varepsilon_{0}$. For the plane stress conditions, he suggested that the coefficient $d_{n}$ be calculated as

$$
d_{n}=\varepsilon_{0}{ }^{1.05 /(n-0.1)} \cdot(1+3 / n)
$$


a)

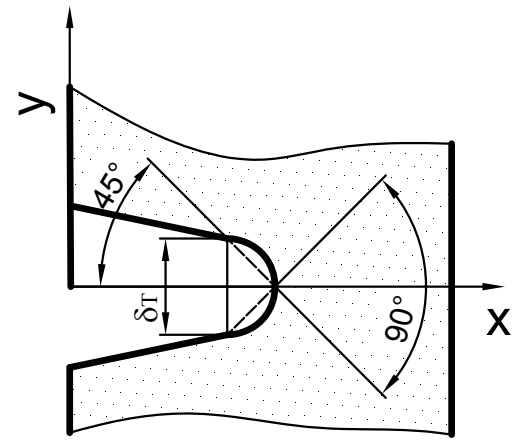

b)

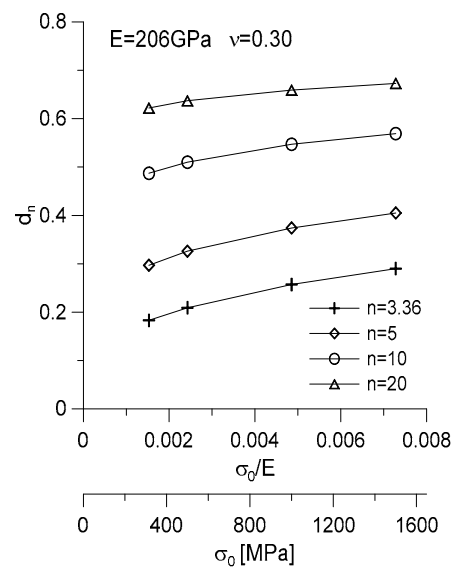

Fig.1. a) Determination of the crack tip opening displacement using the Shih method [11];

b) Values of the coefficient $d_{n}$ (formula (1.3)) for different values of the strain hardening exponent and the yield strength $[3,9]$.

That attempt to determine the coefficient $d_{n}$ was undertaken because of the mutual relationship between the J-integral and the crack tip opening displacement $\delta_{T}$. Later attempts to find a better solution have been numerous yet not always successful. The relationship between the crack tip opening displacement and the J-integral was described extensively in a paper published in 1997 [12]. Prior to that, i.e., in 1995, Gordon et al. [13] had conducted a numerical analysis to study the relationship between the crack tip opening displacement and the J-integral for hypothetical materials with a different degree of material strain hardening (expressed by the strain hardening exponent $\mathrm{n}$ in the RO law), with $\sigma_{0}=\{400,500,600\} \mathrm{MPa}$. The research had been carried out for SEN(B) specimens with a relative crack length $a / W=\{0.1,0.2,0.3,0.5\}$. They had used the results of the numerical calculations to verify the relationship between the J-integral and the crack tip opening displacement in the form

$$
J=m \cdot \sigma_{0} \cdot \delta_{T}
$$

where the value of the coefficient $m$ from a series of experiments is 1 for the plane stress state and 2 for the plane strain state. Using the results of their numerical analysis, the authors [13] proposed that the relationship between the J-integral and the crack tip opening displacement should have the following form

$$
J=m_{T S} \cdot \sigma_{T S} \cdot \delta_{T}
$$

where

$$
\begin{aligned}
& m_{T S}=1.21+0.95 \cdot a / W-0.5 \cdot(a / W)^{2}, \\
& \sigma_{T S}=\sigma_{0} \cdot \frac{(1 /(0.002 \cdot n))^{1 / n}}{\exp ^{1 / n}} .
\end{aligned}
$$

The draft version of the SINTAP procedures [14] include a modified version of formula (1.5) [15], in which the coefficient $m$ is a function of the relative crack length $a / W$ and the ratio of the yield strength $\sigma_{0}$ to the tensile strength $\sigma_{m}$

$$
m=-0.111+0.817 \cdot a / W+1.36 \cdot \sigma_{0} / \sigma_{m} .
$$


However, if a hypothetical material is considered or the value of tensile strength is not known, the following relationship should be used [4, 14]

$$
\sigma_{m}=\sigma_{0} \cdot\left[1+2 \cdot\left(150 / \sigma_{0}\right)^{2.5}\right] .
$$

Each of the approaches is to some extent true; each can be used to analyse a structure containing a crack or to predict fracture toughness after selecting the right fracture criterion [4]. From numerical calculations it is clear that the formulae give completely different results (Fig.2). Figure 2 compares the numerically determined values of the crack tip opening displacement with the values calculated according to formulae (1.3)-(1.10). The comparison was carried out for typical SEN(B) specimens under predominantly plane strain conditions differing in the crack length and the material characteristics.

a)

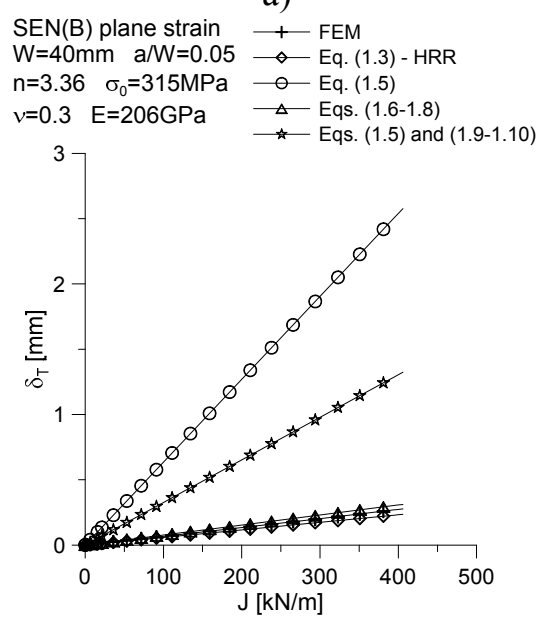

b)

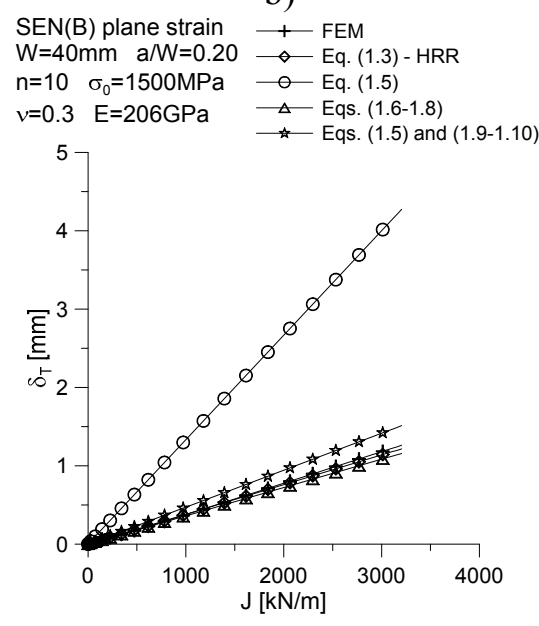

c)

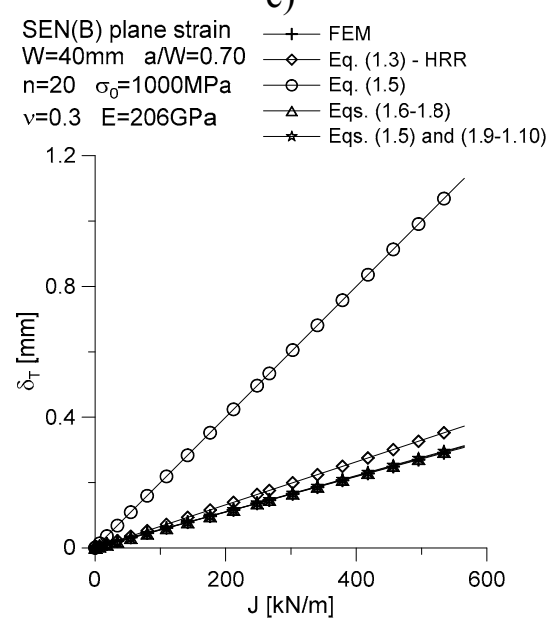

Fig.2. Values of the crack tip opening displacement calculated according to formulae (1.3)-(1.10) compared with the numerical results for various configurations of the material models and relative crack length for SEN(B) specimen: a) $n=3.36, \sigma_{0}=315 \mathrm{MPa}, a / W=0.05$; b) $n=10, \sigma_{0}=1500 \mathrm{MPa}, a / W=0.20$; c) $n=20, \sigma_{0}=1000 \mathrm{MPa}, a / W=0.70$.

The greatest differences between the numerical results and those obtained from formulae (1.3)-(1.10) are observed for specimens with very short cracks $(a / W=0.05)$. The differences decrease when the crack length increases. Figure 3 shows examples of percentage differences between solutions (1.3)-(1.10) and the results estimated using the FEM. In the case of short and very short cracks, the worst goodness of fit is observed when the numerical results are obtained with formula (1.5), or a set of formulae (1.5)-(1.9)-(1.10). As can be seen, the difference between the results obtained through the finite element analysis and those from the other formulae decreases with an increase in the external load $P$, normalised by the limit load $P_{0}$ (see Fig.3), which, for SEN(B) specimens under predominantly plane strain conditions can be calculated as [16]

$$
P_{0}=B \cdot \sigma_{0} \cdot b^{2} /(2 \cdot W)
$$

where $B$ is the specimen thickness (in Ref. [16] it was assumed to be $1 m$ ), $b$ is the length of the uncracked ligament $(b=W-a), W$ is the specimen width and $a$ is the crack length. 
The different approaches described above, which can be used to calculate the crack tip opening displacement in relation to the J-integral, were reviewed by O'Dowd et al. [7-8, 20]. They suggested that the formula take the following form

$$
\delta_{T}=d_{n}\left(\alpha, n, \varepsilon_{0}, Q\right) \cdot \frac{J}{\sigma_{0}} .
$$

As a result, the value of the coefficient $d_{n}$ was dependent on the Q-stresses. However, they did not provide any simple formula to calculate the value of the coefficient $d_{n}\left(\alpha, n, \varepsilon_{0}, \mathrm{Q}\right)$.

a)

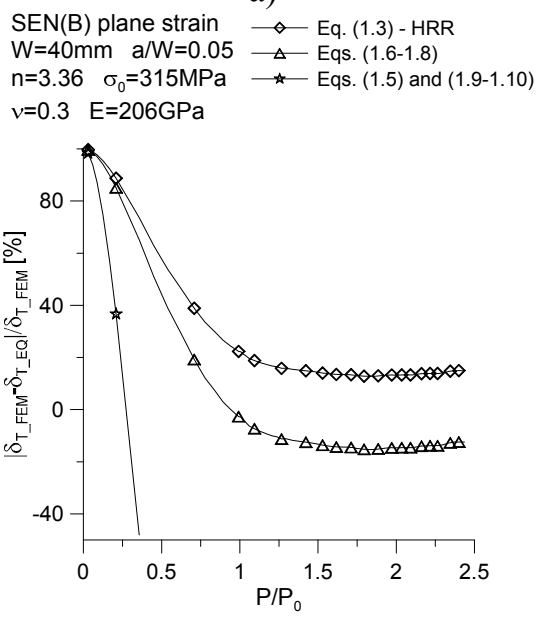

b)

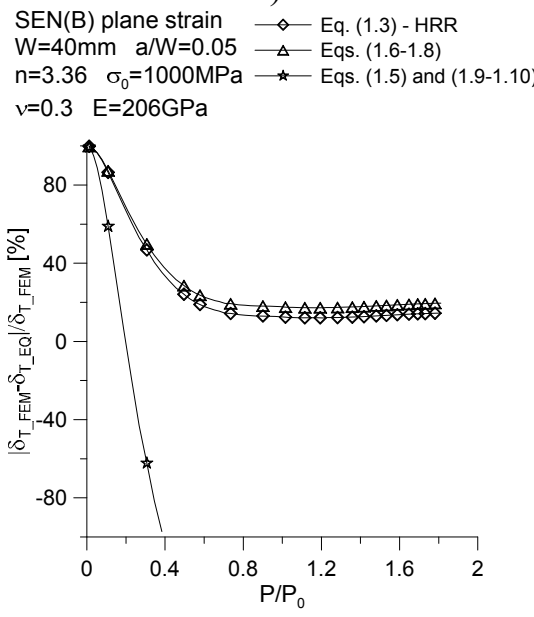

c)

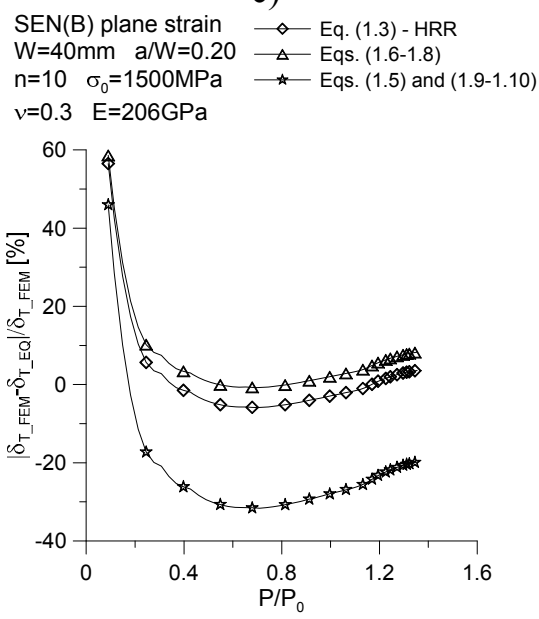

Fig.3. Percentage differences in the crack tip opening displacement between the FE results and the analytical data (formulae (1.3), (1.6)-(1.8) and (1.3)-(1.9)-(1.10), for various configurations of the material models and relative crack length for $\operatorname{SEN}(B)$ specimen: a) $n=3.36, \sigma_{0}=315 \mathrm{MPa}, a / W=0.05$; b) $n=3.36, \sigma_{0}=1000 \mathrm{MPa}, a / W=0.05$; c) $n=10, \sigma_{0}=1500 \mathrm{MPa}, a / W=0.20$.

As in the previous studies, there is no agreement between the numerical and analytical data. If the numerical result is accurate (provided that the FE model satisfies the conditions presented in [3, 17-19]), it is essential to extend the investigations in order to determine the relationships between the crack tip opening displacement and the J-integral (as the pulling force of the crack) and calculate the effect of in-plane constraints (expressed by Q-stresses) on the crack tip opening displacement. The numerical analysis was performed for single edge notched bent (SEN(B)) specimens (Fig.4), which are normally used to study the fracture toughness of a material under predominantly plane strain conditions, as suggested in the relevant standards [21-23]. The value of the J-integral was determined by following the recommendations given in [2123] for SEN(B) specimens under predominantly plane strain conditions and satisfying a series of conditions. The J-integral can be treated as a material constant $\mathrm{J}_{\mathrm{IC}}$, which, after conversion into a critical value of the stress intensity factor $\mathrm{K}_{\mathrm{IC}}$, can be used at the design stage, in accordance with the recommendations provided in the relevant procedures $[19,20]$ and Eurocodes [24]. The value $\mathrm{K}_{\mathrm{IC}}$ can also be obtained by calculating the value of the crack tip opening displacement, determined using appropriate standards [25]. 

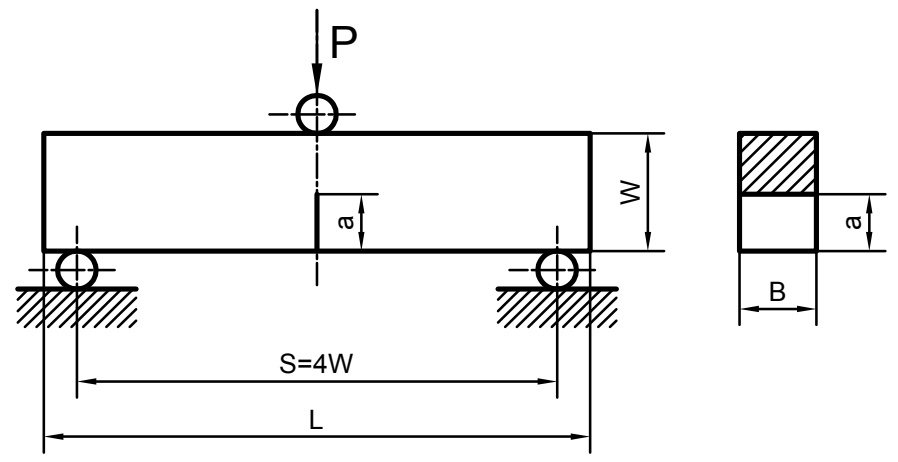

Fig.4. Single-edge notched bend (SEN(B)) specimen $[3-4,16]$.

\section{Details of the numerical calculations}

The numerical calculations were conducted using ADINA SYSTEM $8.8[26,27]$. The FE analysis employed a homogeneous, isotropic model of an elastic-plastic material with the Huber-Misses-Hencky plasticity condition, described by

$$
\frac{\varepsilon}{\varepsilon_{0}}=\left\{\begin{array}{lll}
\sigma / \sigma_{0} & \text { for } & \sigma \leq \sigma_{0} \\
\alpha\left(\sigma / \sigma_{0}\right)^{n} & \text { for } & \sigma>\sigma_{0}
\end{array}\right.
$$

The calculations were carried out assuming that the constant was $\alpha=1$, Young's modulus was $\mathrm{E}=206 \mathrm{GPa}$, Poisson's ratio was $v=0.3$, the four values of the yield strength were $\sigma_{0}=\{315,500,1000$, $1500\} \mathrm{MPa}$ and the four values of the exponent in the RO law were $n=\{3.36,5,10,20\}$. That resulted in a combination of 16 hypothetical stress-strain curves, which can be categorized according to the mechanical properties, obtained for ferritic steels, general-purpose structural steels and materials exhibiting strong and weak strain hardening [28-29].

The numerical model was developed according to the recommendations given in [3, 17-19, 26-27]. Only half of the specimen was modelled and the existing axis of symmetry was used for this purpose. It was necessary to solve a contact problem so that the real behaviour of the specimen could be represented. The load applied to the SEN(B) specimens included a roller - a loading pin. Because of its symmetry the specimen was modelled as a quarter of an arc with a diameter of $16 \mathrm{~mm}$ divided into 90 equal size two-node contact finite elements (FEs). The load was applied to the roller as a displacement linearly increasing with time. The SEN(B) specimen was supported by two pins (support rollers), which were modelled as half an arc with a diameter of $16 \mathrm{~mm}$, also divided into 90 equal size two-node contact finite elements [30]. Figure 5 presents a numerical model of the SEN(B) specimen used in the FEM program.

The modelling of the crack tip of the SEN(B) specimen required considering a quarter of an arc with the radius $r_{w}$ ranging $1 \div 5 \mu \mathrm{m}$. In extreme cases, the radius of the crack tip opening displacement was 40000 and 8000 smaller than the specimen width $\mathrm{W}$. The crack tip was divided into 12 elements. The density of the elements located closer to the edges was higher. Depending on the model, the edge elements were $5 \div 20$ times smaller than the largest elements located in the central part of the arc. The size of the radius of the arc was conditioned by the level of external load as well as the crack length. For each specimen, the area near the crack tip with a radius of about $1.0 \div 5.0 \mathrm{~mm}$ was divided into $36 \div 50$ finite elements. The smallest, located closest to the crack tip, was $20 \div 50$ times smaller than the element located furthest from the crack tip. Thus, in extreme cases, the smallest element, located very close to the crack tip, constituted about $1 / 3024$ or $1 / 10202$ of the specimen width $W$, while the largest element modelling the area near the crack accounted for 
about $1 / 151$ or $1 / 240$ of the specimen width. The parameters of the numerical model were strictly dependent on the geometry (the specimen type, the crack length), the material characteristics and the external load. The analysis was carried out assuming that the deformations and displacements were small [6, 16-18]. The numerical model of the structural element under predominantly plane strain conditions was filled with ninenode finite elements of the 2-D SOLID plane strain type (mixed order interpolation scheme) with nine integration points. The total number of FEs in the model used in the analysis was $6029 \div 6308$, which resulted in $24625 \div 25743$ nodes [30].

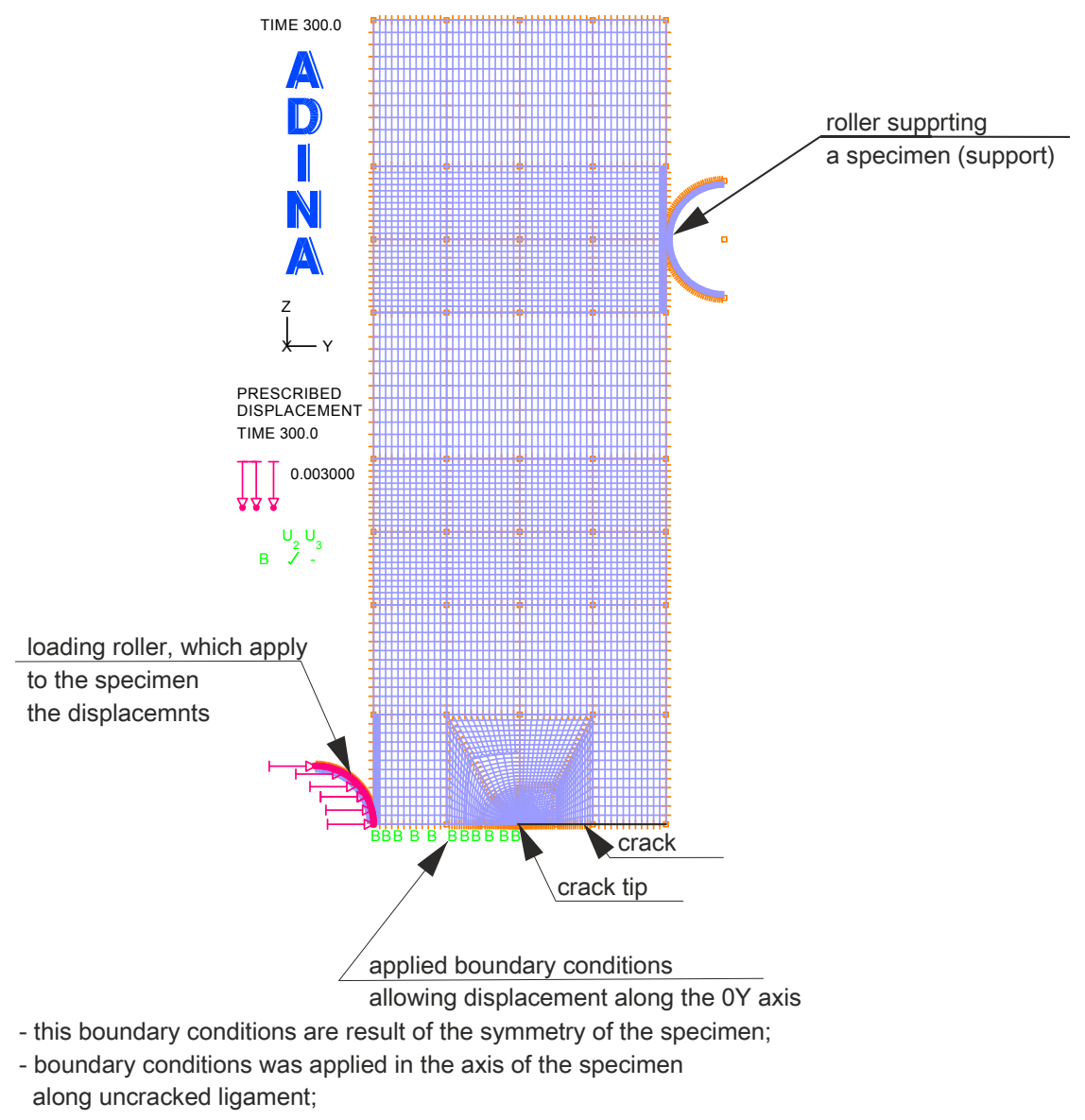

Fig.5. Numerical model of the SEN(B) specimens used in the study.

The numerical analysis performed for a constant width of the SEN(B) specimens, i.e., $W=40 \mathrm{~mm}$, involved modelling the distance between the supports $S=4 \cdot W=160 \mathrm{~mm}$, the total length $L=176 \mathrm{~mm}$ and four relative crack lengths $a / W=\{0.05,0.20,0.50,0.70\}$. The specimens considered had very short, short, normalised $(a / W=0.50)$ and very long cracks. It should be noted that the limit load was verified using 16 specimens differing in the yield strength and the relative crack length. In the elastic-plastic analysis, however, 64 specimens were used taking into account different definitions of the material and different crack lengths. Figure 5 illustrates a numerical model of the SEN(B) specimen used in the FEM program [30].

The J-integral was determined using the virtual shift method [27, 28], based on the concept of virtual crack growth, to calculate the virtual energy shift $[27,28]$. The analysis employed eight integration contours going through the area covering all the FEs within the radius with a length of $\{10,15,20,25,30,35,40,45\}$ FEs near the crack tip. The integration contour was plotted according to the recommendations given in [3, 17-19]. It should be mentioned that the values of the J-integral obtained from the eight integration contours were similar [30]. The crack tip opening displacement $\delta_{\mathrm{T}}$, however, was determined according to the diagram shown in Fig.1a. 


\section{Numerical results}

Figures 6-8 show the influence of the relative crack length $a / W$, the strain hardening exponent $\mathrm{n}$ and the yield strength on the numerically calculated values of the crack tip opening displacement for different geometrical configurations of the SEN(B) specimens and different material characteristics.

a)

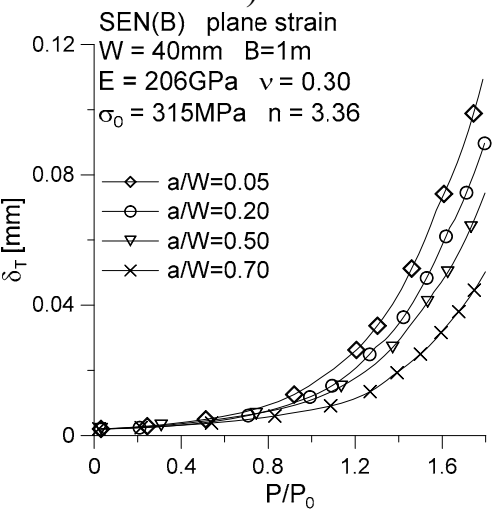

b)

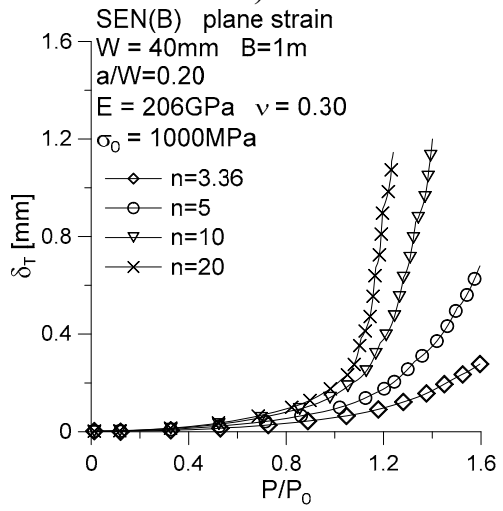

c)

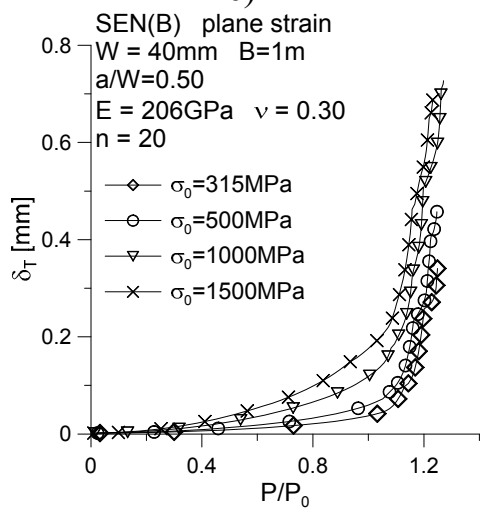

Fig.6. Relationships between (a) the relative crack length $a / W$, (b) the exponent $\mathrm{n}$ in the RO law, (c) the yield strength $\sigma_{0}$ and the crack tip opening displacement $\delta$ determined numerically using the Shih method [31] as a function of the external load

The natural conclusion is that the crack tip opening displacement increases with increasing external load $\mathrm{P}$ normalised by the limit load $P_{0}$, as shown in the plots; the external load can also be expressed by means of the J-integral. The rate of changes is conditioned by the material characteristics and the relative crack length. The shorter the crack length, the higher the values of the crack tip opening displacement $\delta_{T}$ with the level of the external load being the same (Figs 6-7a). It is also clear that the smaller the degree of the material strain hardening (a higher value of the exponent $\mathrm{n}$ in the RO law), the higher the values of the crack tip opening displacement $\delta_{T}$ at the same level of external load (Figs 6-7b). An increase in the yield strength $\sigma_{0}$ is also accompanied by an increase in the crack tip opening displacement $\delta_{T}$ (Fig.6c).

a)

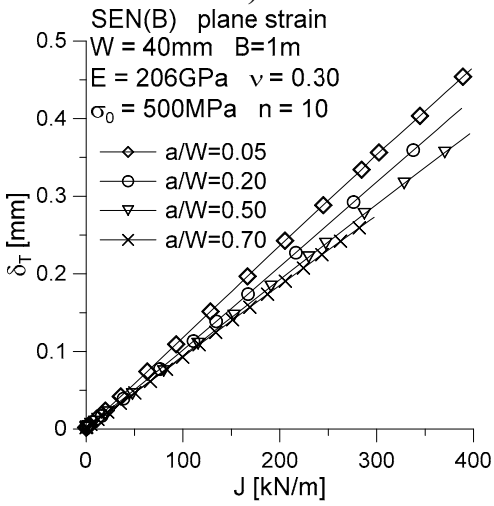

b)

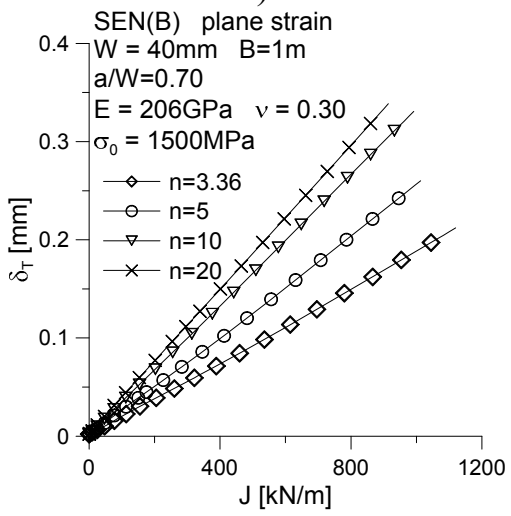

c)

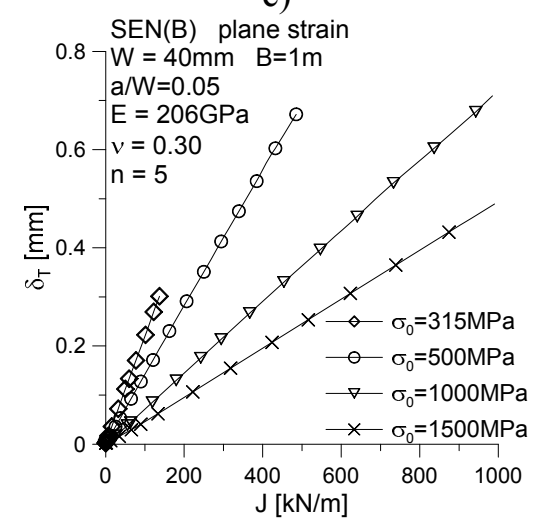

Fig.7. Relationships between (a) the relative crack length $a / W$, (b) the exponent $\mathrm{n}$ in the RO law, (c) the yield strength $\sigma_{0}$ and the value of the crack tip opening displacement $\delta$ determined numerically using the Shih method [31] as a function of the J-integral. 
a)

SEN(B) plane strain

$\mathrm{W}=40 \mathrm{~mm} \quad B=1 \mathrm{~m}$

$\mathrm{E}=206 \mathrm{GPa} \quad v=0.30$

$\sigma_{0}=1000 \mathrm{MPa} \quad \mathrm{n}=5$

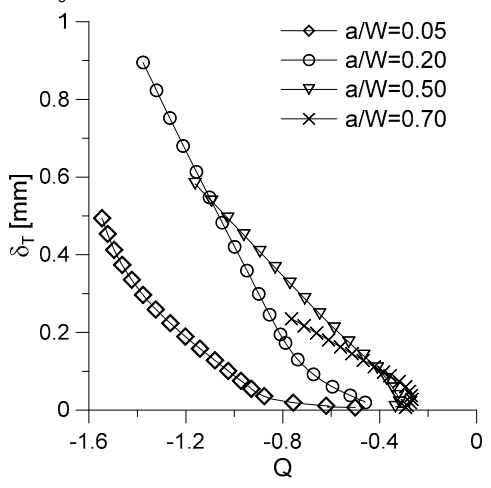

b)

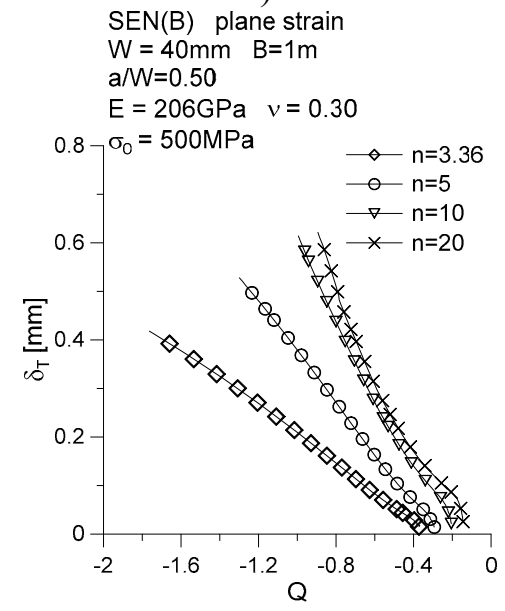

c)

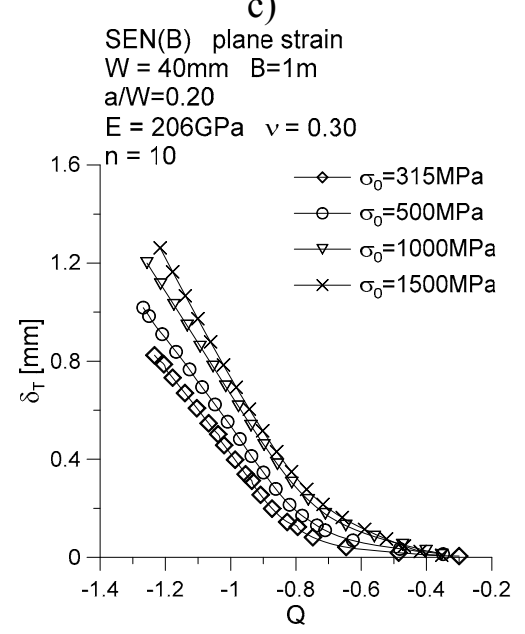

Fig.8. Relationships between (a) the relative crack length $a / W$, (b) the exponent $\mathrm{n}$ in the RO law, (c) the yield strength $\sigma_{0}$ and the value the crack tip opening displacement $\delta$ determined numerically using the Shih method [31] as a function of the Q-stresses - a measure of in-plane constraints [3-4,7-8].

It is interesting to analyse the influence of the level of in-plane constraints (expressed with Q-stresses calculated according to formulae (1.1)-(1.2) on the crack tip opening displacement $\delta_{T}$. As mentioned above, in-plane constraints [3-4] are treated as the resistance offered by the material of a structural element to plastic deformations. In fracture mechanics, in-plane constraints are generally determined for predominantly plane strain conditions using Q-stresses defined by O'Dowd [7-8], which are the difference between actual stresses in the structural element (established by means of FEs) and the HRR solution [1-2] calculated according to the theoretical formulae. In the case of plane strain state, Q-stresses generally have a non-zero value. When the level of in-plane constraints is low, which is characteristic of specimens with short and very short cracks, the value of the Q-stresses is negative; however, when the level of in-plane constraints is high, which is typical of specimens containing long cracks, the value of the Q-stresses is high [3-4].

From the analysis of the numerical results it is evident that an increase in the external load causes the level of in-plane constraints to fall (the Q-stresses show increasingly negative values). This is accompanied by a rise in the crack tip opening displacement $\delta_{T}$ (Fig.8). The shorter the crack, the smaller the in-plane constraints (Fig.8a). An increase in the degree of material hardening leads to a drop in the values of the inplane constraints, while the crack tip opening displacement $\delta_{T}$ remains constant (Fig.8b). It can be concluded that for materials where strain hardening becomes increasingly worse, the values of the crack tip opening displacement increase at the same level of the in-plane constraints (Fig.8b). The higher the yield strength, the greater the in-plane constraints (Fig.8c). When the value of Q-stresses does not change, the values of the crack tip opening displacement $\delta_{\mathrm{T}}$ are higher for materials described with a higher value of yield strength. Using the numerical results presented above, we can apply the formula proposed by O'Dowd et al. (formula (1.12)) [7-8], which relates the crack tip opening displacement $\delta_{T}$ with the J-integral through the coefficient $d_{n}$. In the calculations it was assumed that $\alpha=1$, thus we can write that

$$
\delta_{T}=d_{n}\left(n, \sigma_{0} / E, Q\right) \cdot \frac{J}{\sigma_{0}} .
$$

Figures 9-11 show the coefficient $d_{n}\left(n, \sigma_{0} / \mathrm{E}, \mathrm{Q}\right)$ against Q-stresses (a measure of in-plane constraints), the J-integral and the external load $\mathrm{P}$ normalised by the limit load $P_{0}$. From the plots it is clear 
that, first, the coefficient $d_{n}\left(n, \sigma_{0} / \mathrm{E}, \mathrm{Q}\right)$ decreases with increasing external load and, then, after $P / P_{0}$ exceeds 1, it reaches a certain level of saturation. This suggests that a decrease in the level of in-plane constraints causes the coefficient $d_{n}\left(n, \sigma_{0} / \mathrm{E}, \mathrm{Q}\right)$ to increase until it reaches a state of saturation (Fig.9). Since Q-stresses are dependent on the relative crack length $a / W$ and the material characteristics (through $n$ and the ratio $\left.\sigma_{0} / \mathrm{E}\right)$, the coefficient $d_{n}$ is assumed to be a function in the form of $d_{n}=d_{n}\left(n, \sigma_{0} / \mathrm{E}, a / W\right)$. Table 1 shows values of the coefficient $d_{n}\left(n, \sigma_{0} / \mathrm{E}, a / W\right)$ determined for the state of saturation of the $d_{n}\left(n, \sigma_{0} / \mathrm{E}\right.$, $a / W)=f(J)$ curves.

a)

SEN(B) plane strain

$\mathrm{W}=40 \mathrm{~mm} \quad B=1 \mathrm{~m}$

$\mathrm{E}=206 \mathrm{GPa} \quad v=0.30$

$\sigma_{0}=1000 \mathrm{MPa} \mathrm{n}=5$

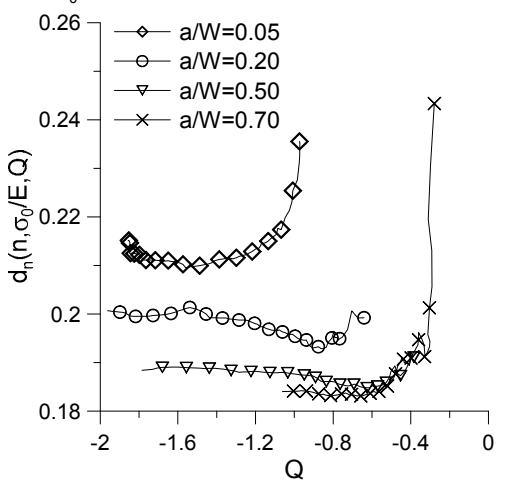

b)

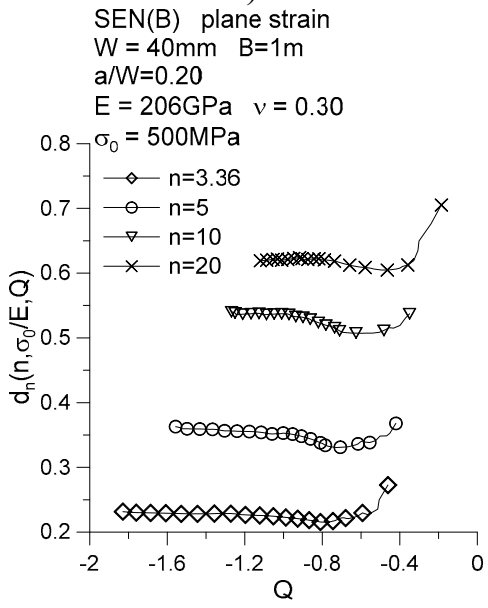

c)

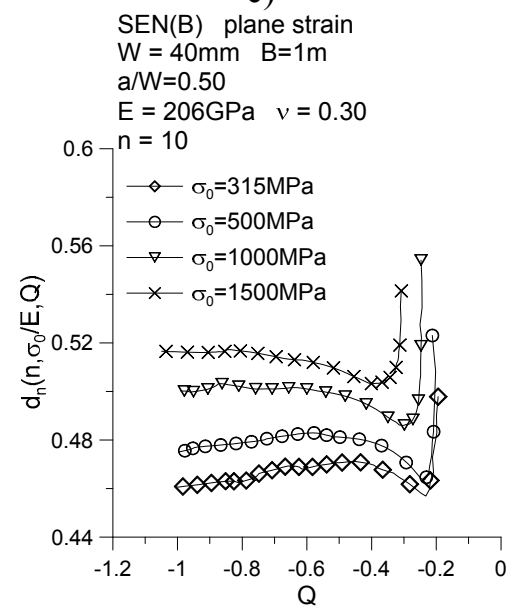

Fig.9. Relationships between (a) the relative crack length $a / W$, (b) the exponent $n$ in the RO law, (c) the yield strength $\sigma_{0}$ and the coefficient $d_{n}\left(n, \sigma_{0} / \mathrm{E}, \mathrm{Q}\right)$ as a function of the level of in-plane constraints expressed by Q-stresses.

a)

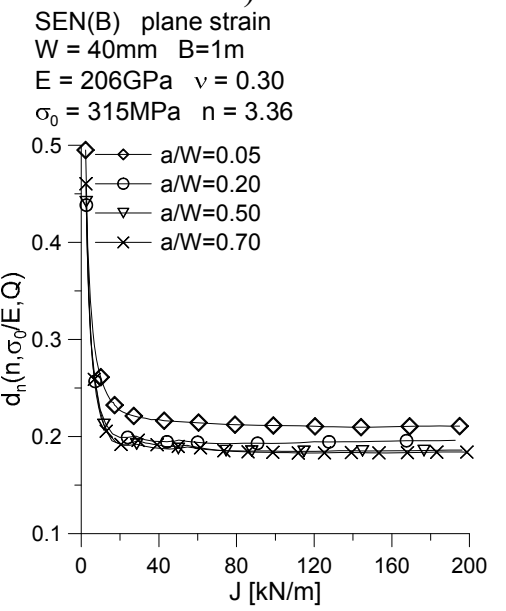

b)

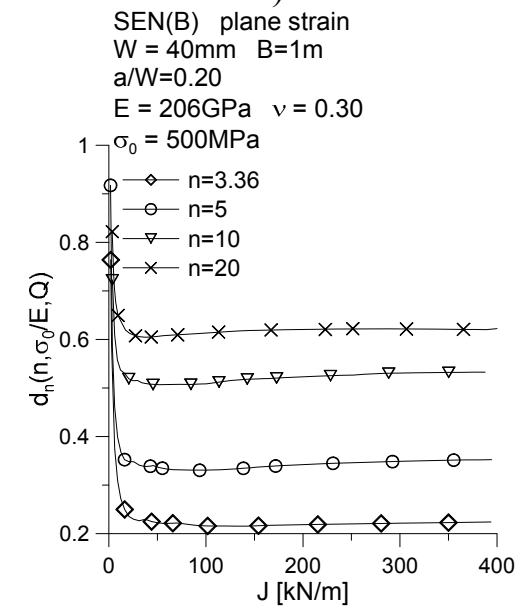

c)

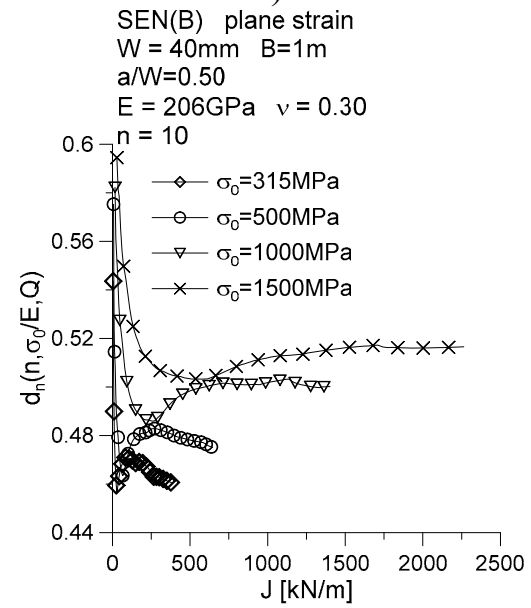

Fig.10. Relationships between (a) the relative crack length $a / W$, (b) the exponent $n$ in the RO law, (c) the yield strength $\sigma_{0}$ and the coefficient $d_{n}\left(n, \sigma_{0} / \mathrm{E}, \mathrm{Q}\right)$ as a function of the J-integral $\mathrm{J}$. 
a)

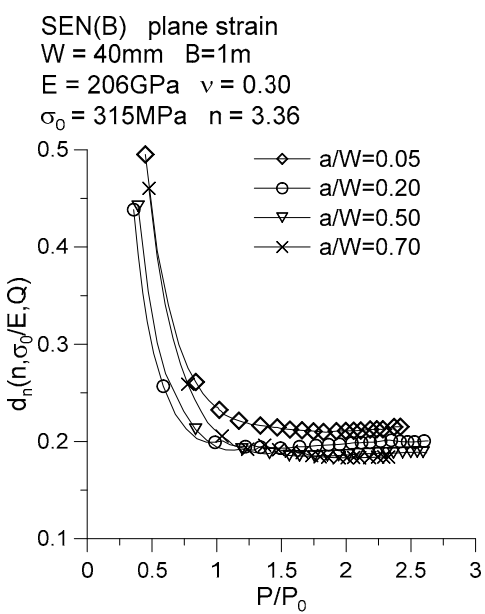

b)

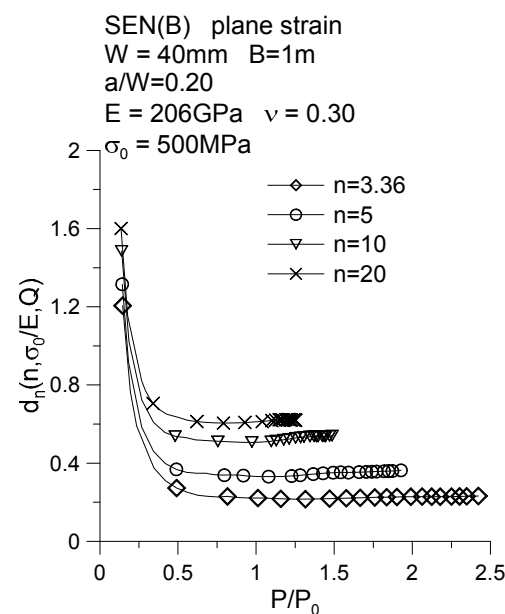

c)

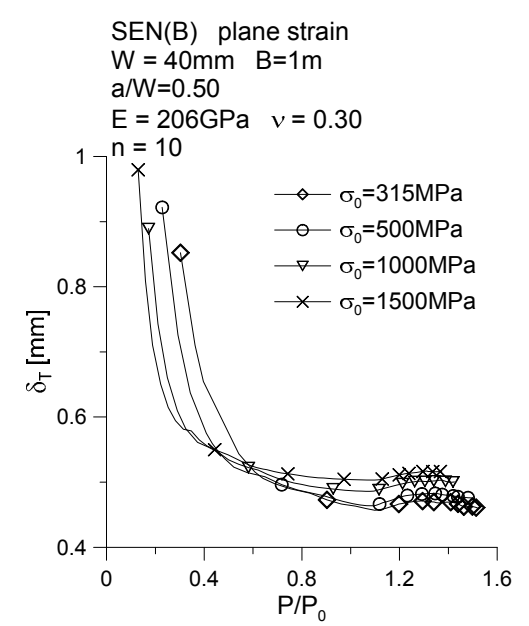

Fig.11. Relationships between (a) the relative crack length $a / W$, (b) the exponent $n$ in the RO law, (c) the yield strength $\sigma_{0}$ and the coefficient $d_{n}\left(n, \sigma_{0} / \mathrm{E}, \mathrm{Q}\right)$ as a function of the external load $P$ normalised by the limit load $P_{0}$.

Table 1. Values of the coefficient $d_{n}\left(n, \sigma_{0} / \mathrm{E}, a / W\right)$ determined for the state of saturation of the $d_{n}\left(n, \sigma_{0} / \mathrm{E}, \mathrm{Q}\right.$ $a / W)=f(J)$ curves.

\begin{tabular}{|c|c|c|c|c|c|}
\hline \multirow{2}{*}{$n$} & \multirow{2}{*}{$a / W$} & $\begin{array}{c}\sigma_{0}=315 \mathrm{MPa} \\
\left(\sigma_{0} / \mathrm{E}=0.00153\right)\end{array}$ & $\begin{array}{c}\sigma_{0}=500 \mathrm{MPa} \\
\left(\sigma_{0} / \mathrm{E}=0.00243\right)\end{array}$ & $\begin{array}{c}\sigma_{0}=1000 \mathrm{MPa} \\
\left(\sigma_{0} / \mathrm{E}=0.00485\right)\end{array}$ & $\begin{array}{c}\sigma_{0}=1500 \mathrm{MPa} \\
\left(\sigma_{0} / \mathrm{E}=0.00728\right)\end{array}$ \\
\hline 3.36 & 0.05 & 0.213 & 0.245 & 0.299 & 0.329 \\
\hline 3.36 & 0.2 & 0.200 & 0.229 & 0.275 & 0.314 \\
\hline 3.36 & 0.5 & 0.189 & 0.215 & 0.260 & 0.290 \\
\hline 3.36 & 0.7 & 0.184 & 0.209 & 0.252 & 0.281 \\
\hline 5 & 0.05 & 0.343 & 0.377 & 0.436 & 0.469 \\
\hline 5 & 0.2 & 0.328 & 0.358 & 0.407 & 0.437 \\
\hline 5 & 0.5 & 0.299 & 0.331 & 0.372 & 0.397 \\
\hline 5 & 0.7 & 0.296 & 0.321 & 0.358 & 0.381 \\
\hline 10 & 0.05 & 0.553 & 0.586 & 0.622 & 0.645 \\
\hline 10 & 0.2 & 0.508 & 0.537 & 0.569 & 0.587 \\
\hline 10 & 0.5 & 0.462 & 0.478 & 0.501 & 0.516 \\
\hline 10 & 0.7 & 0.448 & 0.462 & 0.485 & 0.500 \\
\hline 20 & 0.05 & 0.683 & 0.693 & 0.721 & 0.740 \\
\hline 20 & 0.2 & 0.607 & 0.621 & 0.643 & 0.658 \\
\hline 20 & 0.5 & 0.538 & 0.548 & 0.563 & 0.573 \\
\hline 20 & 0.7 & 0.522 & 0.531 & 0.545 & 0.556 \\
\hline
\end{tabular}


a)

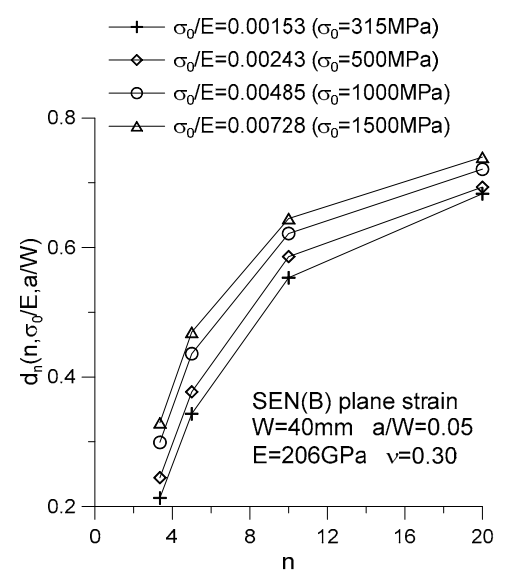

b)

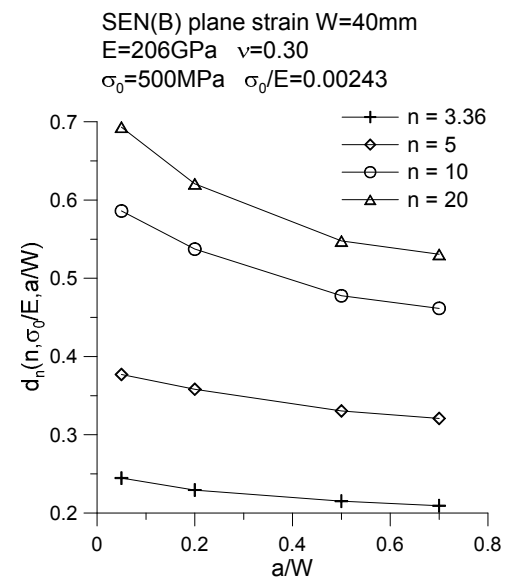

c)

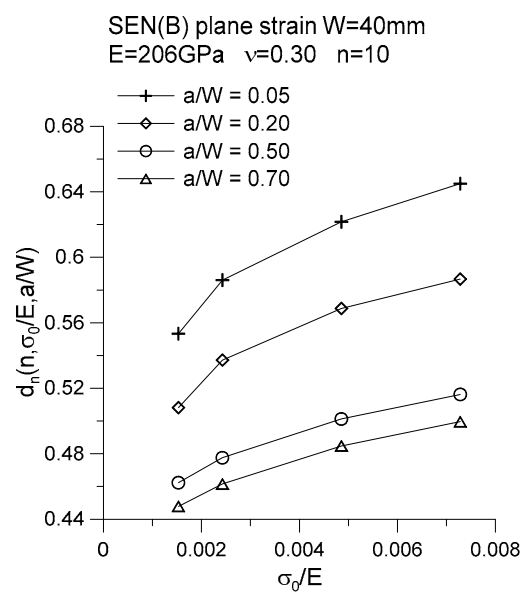

Fig.12. Relationships between (a) the yield strength $\sigma_{0}$, (b) the exponent $n$ in the RO law, (c) the relative crack length $a / W$ and the coefficient $d_{n}\left(n, \sigma_{0} / \mathrm{E}, a / W\right)$ for $\operatorname{SEN}(\mathrm{B})$ specimens with different geometrymaterial configurations.

Figure 12 shows the relationship between the coefficient $d_{n}\left(n, \sigma_{0} / \mathrm{E}, a / W\right)$ and the parameters affecting the level of the geometric constraints. The value of the coefficient $d_{n}$ is strongly dependent on the exponent $\mathrm{n}$ (Fig.12a and Fig.12b); the greater the strain hardening of the material, the higher the value of the coefficient $d_{n}$. The higher the yield strength, the higher the value of the coefficient $d_{n}$ (Figs 12a and 12c). An increase in the crack length results in a decrease in the coefficient $d_{n}$ (Figs $12 \mathrm{~b}$ and $12 \mathrm{c}$ ).

It is fully justified to analyse the values of the coefficient $d_{n}\left(n, \sigma_{0} / \mathrm{E}, a / W\right)$ in the saturation state achieved for the external load $\mathrm{P}$ satisfying the condition $P / P_{0} \geq 1.0$. Most materials fracture after they reach full plasticity, i.e., when the external load is equal to or greater than the value of the limit load. Sumpter and Forbes [31] used the example of mild steel with $\sigma_{0}=315 \mathrm{MPa}$ and $n=5$ to show that the material reached a critical value of the J-integral $(J=40 \mathrm{kN} / \mathrm{m})$ when the limit load was $P / P_{0} \approx 1.25$.

\section{Approximation of selected numerical results}

The results of the numerical analysis presented in this paper can be used to determine the values of the crack tip opening displacement for SEN(B) specimens under predominantly plane strain conditions when the value of the J-integral is known. The value can be calculated using hybrid solutions presented in [30]. Some of the numerical results were approximated to simplify the calculations. The approximation was performed for the FE results, determined for the saturation state of the $d_{n}\left(n, \sigma_{0} / \mathrm{E}, a / W\right)=f(J)$ curves. It was essential to generate three-dimensional surface plots of $d_{n}=f\left(n, \sigma_{0} / \mathrm{E}\right)$ for the specimens according to the relative crack length (Fig.13a). Then, Table Curve 3D [32] was applied to describe the resultant surfaces on the basis of the following formula

$$
d_{n}\left(n, \sigma_{0} / E, a / W\right)=a_{1}+b_{1} \cdot \ln \left(\sigma_{0} / E\right)+c_{1} \cdot(n)^{d_{1}}
$$

where the coefficients $a_{1}, b_{1}, c_{1}$ and $d_{1}$ are functions of the relative crack length $a / W$. The values of the approximation coefficients $a_{1} . . d_{1}$ are provided in Tab.2.

For convenience, additional formulae could be used to determine the values of the coefficients $a_{1} . . d_{1}$ 


$$
\begin{aligned}
& a_{1}(a / W)=-5.6957 \cdot(a / W)^{3}+8.5515 \cdot(a / W)^{2}-4.241 \cdot(a / W)+1.5734, \\
& b_{1}(a / W)=0.011 \cdot(a / W)^{3}+0.0191 \cdot(a / W)^{2}-0.0508 \cdot(a / W)+0.0652, \\
& c_{1}(a / W)=-8.2892 \cdot(a / W)^{3}+10.394 \cdot(a / W)^{2}-3.2233 \cdot(a / W)-1.242, \\
& \left\{\begin{array}{lll}
d_{1}(a / W)=-3.3333 \cdot(a / W)-0.3333 & \text { for } & a / W=\langle 0.05,0.20\rangle \\
d_{1}(a / W)=-1 & \text { for } & a / W=\langle 0.20,0.70\rangle
\end{array}\right.
\end{aligned}
$$

For each of the formulae, the coefficient of regression was $R^{2}=1$. Figure 14 compares the approximation results (formulae 3.1-4.5) with the numerical data.

a)

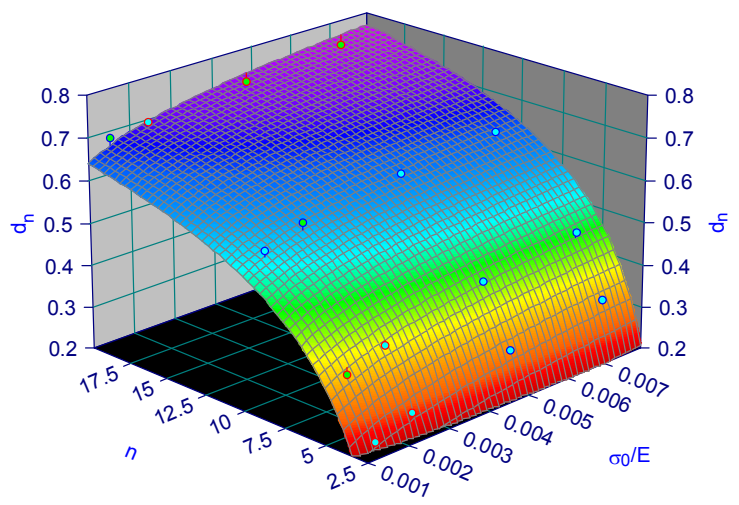

b)

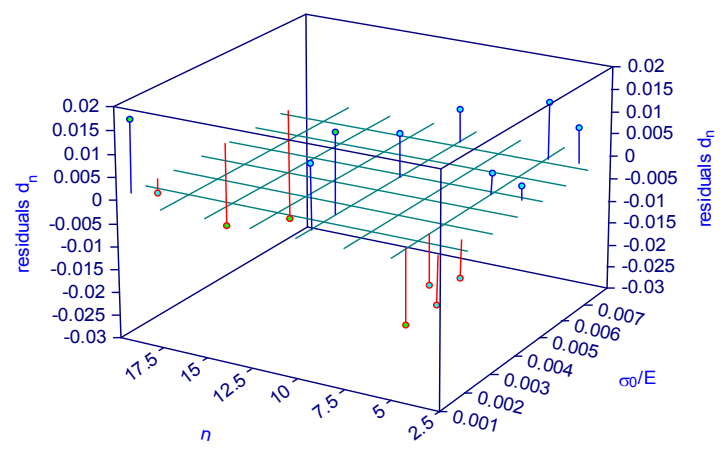

Fig.13. a) An example diagram of the surface used to approximate the data $d_{n}=f\left(n, \sigma_{0} / \mathrm{E}\right)$ for $\operatorname{SEN}(\mathrm{B})$ specimens with the relative crack length $a / W=0.05 ; \mathrm{b}$ ) Graphical representation of the differences between the numerical results and the approximation data using formula (4.1) with the coefficient being $d_{n}=f\left(n, \sigma_{0} / \mathrm{E}\right)$ for $\operatorname{SEN}(\mathrm{B})$ specimens with the relative crack length $a / W=0.05$.

Table 2. Values of the approximation coefficients $a_{1} . . d_{l}$ dependent on the relative crack length $a / W$ required in Eq.(4.1) to calculate the function $d_{n}\left(n, \sigma_{0} / \mathrm{E}, a / W\right)$.

\begin{tabular}{|c|c|c|c|c|c|}
\hline$a / W$ & $a_{1}$ & $b_{1}$ & $c_{1}$ & $d_{1}$ & $R^{2}$ \\
\hline 0.05 & 1.3821 & 0.0627 & -1.3782 & -0.5 & 0.994 \\
\hline 0.20 & 1.0217 & 0.0559 & -1.5372 & -1.0 & 0.992 \\
\hline 0.50 & 0.8788 & 0.0460 & -1.2914 & -1.0 & 0.990 \\
\hline 0.70 & 0.8413 & 0.0428 & -1.2485 & -1.0 & 0.992 \\
\hline
\end{tabular}




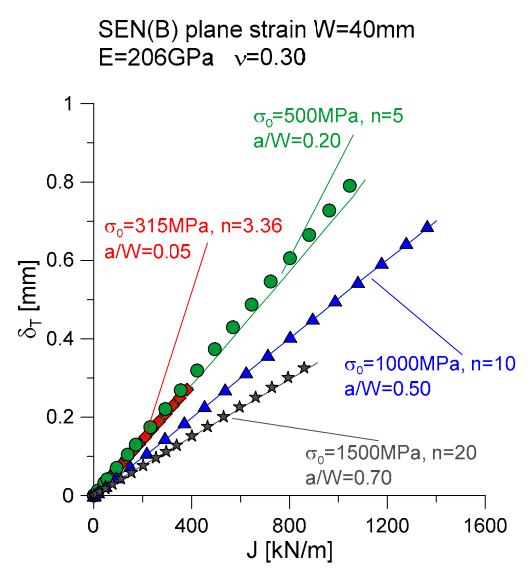

Fig.14. Numerical data (solid lines) compared with the approximation results (circles, triangles and stars) obtained with formulae (3.1)-(4.5)

If the approximation of the coefficient $d_{n}\left(n, \sigma_{0} / \mathrm{E}, a / W\right)$ with formulae (4.1)-(4.5) gives unsatisfactory results, it is recommended to use another approximation formula

$$
\begin{aligned}
& d_{n}\left(n, \sigma_{0} / E, a / W\right)=a_{2}+b_{2} \cdot\left(\sigma_{0} / E\right)+c_{2} /(n)+d_{2} \cdot\left(\sigma_{0} / E\right)^{2}+e_{2} /(n)^{2}+ \\
& +f_{2} \cdot\left(\sigma_{0} / E\right) /(n)+g_{2} \cdot\left(\sigma_{0} / E\right)^{3}+h_{2} /(n)^{3}+ \\
& +i_{2} \cdot\left(\sigma_{0} / E\right) /(n)^{2}+j_{2} \cdot\left(\sigma_{0} / E\right)^{2} /(n) .
\end{aligned}
$$

The values of the coefficients $a_{2 .} . j_{2}$, dependent on the relative crack length, are presented in Tab.3.

Table 3. Values of the approximation coefficients $a_{2} . . d_{2}$ dependent on the relative crack length $a / W$ required in Eq.(4.6) to calculate the $d_{n}\left(n, \sigma_{0} / \mathrm{E}, a / W\right)$ function.

\begin{tabular}{|c|c|c|c|c|}
\hline & $a / W=0.05$ & $a / W=0.20$ & $a / W=0.50$ & $a / W=0.70$ \\
\hline$a_{2}$ & 0.7749 & 0.7749 & 0.5837 & 0.5689 \\
\hline$b_{2}$ & 29.4251 & 29.4251 & 24.1249 & 19.1304 \\
\hline$c_{2}$ & -2.9126 & -2.9126 & -1.5587 & -1.4705 \\
\hline$d_{2}$ & -5776.9 & -5776.9 & -5518.3 & -3999.5 \\
\hline$e_{2}$ & 0.6943 & 0.6943 & -2.1733 & -1.9054 \\
\hline$f_{2}$ & 223.3 & 223.3 & 166.4 & 131.8 \\
\hline$g_{2}$ & 360681.4 & 360681.4 & 371065.5 & 268116.4 \\
\hline$h_{2}$ & 6.1441 & 6.1441 & 7.2443 & 6.0984 \\
\hline$i_{2}$ & -369.5 & -369.5 & -213.4 & -129.7 \\
\hline$j_{2}$ & -6067.5 & -6067.5 & -4940.4 & -4800.6 \\
\hline$R^{2}$ & 0.9998 & 0.9998 & 0.9998 & 0.9999 \\
\hline
\end{tabular}


If there is a need to determine the value of the coefficient $d_{n}$ for a geometry-material configuration not studied before, and there exist no recommendations, it is vital to find a solution for two cases of a configuration that is most similar to the desired one and use the data for linear approximation.

The best results would be reported for a case when the formulae given described changes in the coefficient $d_{n}\left(n, \sigma_{0} / \mathrm{E}, a / W\right)$ against the external load, which can be expressed by the J-integral. The author is currently working on the code of a computer program that would contain all the numerical data with approximations to be used in engineering analysis.

\section{Conclusion}

This paper has examined the effects of the in-plane geometric constraints expressed by Q-stresses on the crack tip opening displacement $\delta_{T}$ for typical SEN(B) specimens under predominantly plane strain conditions. The work has briefly discussed the existing relationships between the crack tip opening displacement $\delta_{T}$ and the J-integral. Details of the numerical modelling have also been given. Reference [32] shows the relationship between the in-plane constraints, i.e., Q-stresses, the relative crack length and the material characteristics expressed by the yield strength $\sigma_{0}$ and the strain hardening exponent $\mathrm{n}$. The findings of the study described in [33] were used to determine the relationship between the crack tip opening displacement and the external load $\mathrm{P}$ normalised by the limit load $P_{0}$, the J-integral and the Q-stresses $-\mathrm{a}$ measure of the in-plane constraints. The research involved studying how the relative crack length was dependent on the material characteristic. The analysis results were used to propose a new formula to calculate the value of the coefficient $d_{n}\left(n, \sigma_{0} / \mathrm{E}, a / W\right)$ while taking into account the effect of the in-plane constraints on the strain hardening exponent $n$, the ratio $\sigma_{0} / \mathrm{E}$ and the relative crack length $a / W$.

As shown above, the proposed formula would definitely be more accurate if the influence of the external load on the coefficient $d_{n}\left(n, \sigma_{0} / \mathrm{E}, a / W\right)$ was considered. The use of the coefficient $d_{n}\left(n, \sigma_{0} / \mathrm{E}, a / W\right)$ for the saturation state would provide satisfactory results in the assessment of the crack tip opening displacement dependent on the J-integral. In the near future, the author intends to develop a computer program, which will be a collection of numerical results and their approximations to be used in theoretical considerations and engineering analysis.

\section{Acknowledgement}

The research reported herein was supported by a grant from the Ministry of Science and Higher Education (IUVENTUS PLUS No. IP2012 011872).

\section{Nomenclature}

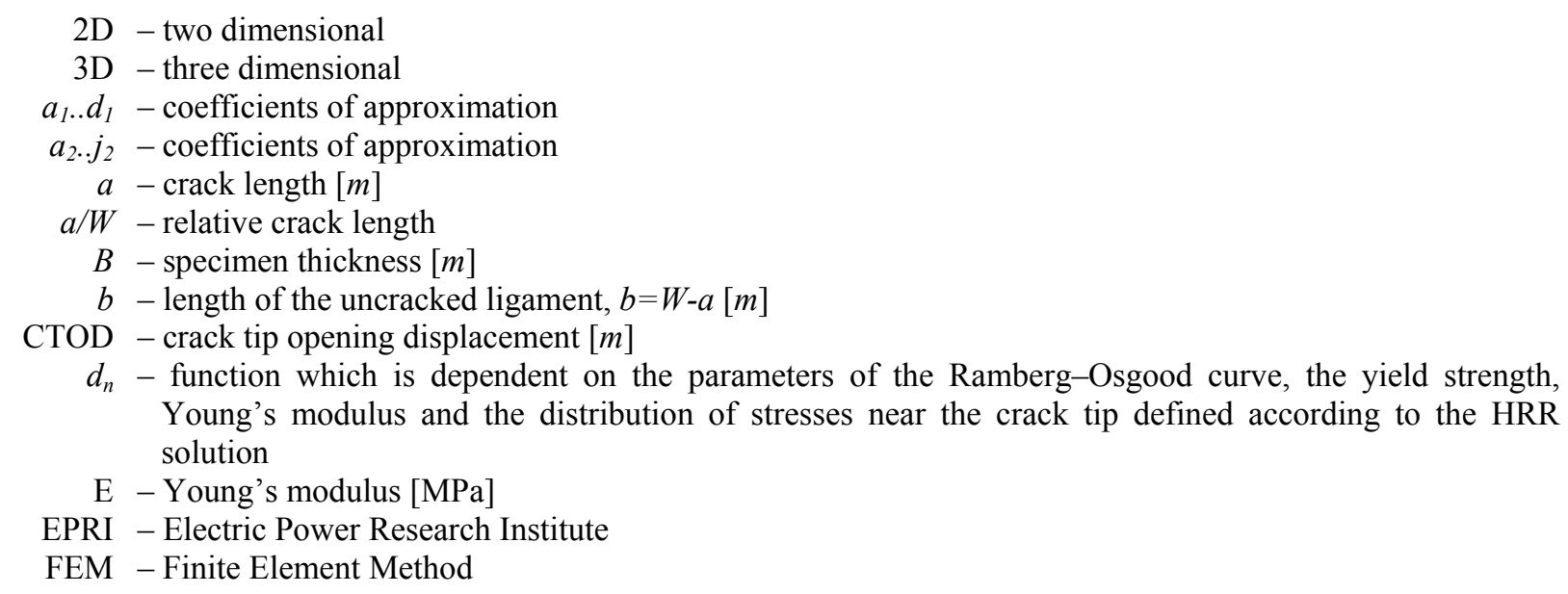


$f(a / W)$ - geometry function used for the approximation of the numerical results

$I_{n}$ - quantity dependent on the material through the exponent $n$, the method of loading and the specimen thickness, which defines whether plane stress or plane strain conditions are predominant

$i, j$ - components of the stress tensor

$J$ - J-integral $[\mathrm{N} / \mathrm{m}]$

$K_{I C}-$ critical value of the stress intensity factor $\left[\mathrm{MPa} \cdot m^{0.5}\right]$

$L$ - specimen length $[m]$

$n$ - exponent in the Ramberg-Osgood (RO) law

$Q$ - the $Q$-stress parameter defined by O'Dowd and Shih as a difference between the FEM and HRR stress distributions

$P$ - external load $[k N]$

$P_{0}-$ limit load $[k N]$

$r_{w}$ - radius of the arc in crack tip $[m]$

$r, \theta$ - coordinates of the polar coordinate system hooked on crack tip

SEN(B) - single edge notched specimen in bending

$T_{z}$ - the stress triaxiality parameter defined by Guo Wanlin as $T_{z}=\sigma_{33} /\left(\sigma_{11}+\sigma_{22}\right)$

$v_{L L}-$ load line displacement $[m]$

$W$ - specimen width $[m]$

$x_{1}, x_{2}, x_{3}$-Cartesian coordinates: $x_{1}, x_{2}$ - in the crack plane, $x_{3}$ - in the thickness direction

$x_{3} / B$ - normalized coordinate in the thickness direction $\left(x_{3} / B=0-\right.$ center of the specimen, $x_{3} / B=0.5-$ free surface of the specimen)

$\alpha$ - material constant in the RO law

$\delta_{T}$ - crack tip opening displacement (CTOD) $[m]$

$\varepsilon_{0}-$ strain corresponding to the yield strength, calculated as $\varepsilon_{0}=\sigma_{0} / E$

$\left(\sigma_{\theta \theta}\right)_{\mathrm{FEM}}-$ numerical value of stresses

$\left(\sigma_{\theta \theta}\right)_{\mathrm{HRR}}$ - the value of stresses resulting from the HRR solution

$\tilde{\sigma}_{i j}(\theta, n)$ - functions dependent on the material through the exponent $n$, the angle $\theta$ and on the specimen thickness, according to the dominance of the plane stress or plane strain state

$v$ - Poisson's ratio

$\sigma_{0}-$ yield stress $[\mathrm{MPa}]$

\section{References}

[1] Hutchinson J.W. (1968): Singular behaviour at the end of a tensile crack in a hardening material. - Journal of the Mechanics and Physics of Solids, vol.16, No.1, pp.13-31.

[2] Rice J.R. and Rosengren G.F. (1968): Plane strain deformation near a crack tip in a power-law hardening material. - Journal of the Mechanics and Physics of Solids, vol.16, No.1, pp.1-12.

[3] Graba M. (2009): Numerical analysis of the mechanical fields near the crack tip in the elastic-plastic materials. 3D problems. - PhD dissertation, Kielce University of Technology - Faculty of Mechatronics and Machine Building, 387 pages, Kielce 2009 (in Polish).

[4] Neimitz A., Dzioba I., Graba M. and Okrajni J. (2008): The Assessment of the Strength and Safety of the Operation High Temperature Components Containing Crack. - Kielce University of Technology Publishing House, Kielce.

[5] Neimitz A., Dzioba I., Molasy R. and Graba M. (2004): The influence of the constraints on fracture toughness. Proceeding of the XX Symposium of Fatigue and Fracture Mechanics, Bydgoszcz-Pieczyska, 27-30.04.2004, pp.265-272 (in Polish).

[6] Neimitz A., Graba M. and Gałkiewicz J. (2007): An alternative formulation of the Ritchie-Knott-Rice local fracture criterion. - Engineering Fracture Mechanics, vol.74, pp.1308-1322.

[7] O'Dowd N.P. and Shih C.F. (1991): Family of crack-tip fields characterized by a triaxiality parameter - I. Structure of fields. - J. Mech. Phys. Solids, vol.39, No.8, pp. 989-1015. 
[8] O'Dowd N.P. and Shih C.F. (1992): Family of crack-tip fields characterized by a triaxiality parameter - II. Fracture applications. - J. Mech. Phys. Solids, vol.40, No.5, pp.939-963.

[9] Gałkiewicz J. and Graba M. (2006): Algorithm for determination of $\tilde{\sigma}_{i j}(n, \theta), \tilde{\varepsilon}_{i j}(n, \theta), \quad \tilde{u}_{i}(n, \theta), d_{n}(n)$ and $I_{n}(n)$ functions in Hutchinson-Rice-Rosengren solution and its $3 D$ generalization. - Journal of Theoretical and Applied Mechanics, vol.44, No.1, pp.19-30.

[10] Wells A.A. (1961): Unstable crack propagation in metals: cleavage and fast fracture. - Proceedings of the Crack Propagation Symposium, tom 1, Paper 84, Cranfield, UK

[11] Shih C.F. (1981): Relationship between the J-integral and the crack opening displacement for stationary and extending cracks. - Journal of the Mechanics and Physics of Solids, vol.29, pp.305-329.

[12] Omidvar B., Wnuk M.P. and Choroszynski M. (1997): Relationship between the CTOD and the J integral for stationary and growing cracks. - Closed form solutions, International Journal of Fracture 87: pp.331-343.

[13] Gordon J.R., Neale B.K. and Wang Y-Y. (1995): A comparison of J and CTOD as elastic-plastic fracture characterizing parameters, constraint effects in fracture theory and application. - Second Volume, ASTM STP 1244, M. Kirk and A. Bakker, ASTM Philadelphia, pp.425-444.

[14] SINTAP: Structural Integrity Assessment Procedures for European Industry. - Final Procedure, Brite-Euram Project No BE95-1426. - Rotherham: British Steel, 1999.

[15] DRAFT NOTE - J.T. Martin - OGBM/3, R.W.J. Koers - OGBM/3, CTOD versus J-Integral as a fracture parameter, 25042001 - SINTAP, April 8, 1998

[16] Kumar V., German M.D. and Shih C.F. (1981): An engineering approach for elastic-plastic fracture analysis Electric Power Research Institute, Inc. Palo Alto, CA (1981), EPRI Report NP-1931.

[17] Graba M. and Gałkiewicz J. (2007): Influence of the crack tip model on results of the finite element method. Journal of Theoretical and Applied Mechanics, Warsaw, vol.45, No.2, pp.225-237.

[18] Brocks W., Cornec A. and Scheider I. (2003): Computational aspects of nonlinear fracture mechanics. Bruchmechanik, GKSS-Forschungszentrum, Geesthacht, Germany, Elsevier pp.127-209.

[19] Brocks W. and Scheider I. (2003): Reliable J-values. Numerical aspects of the path-dependence of the Jintegral in incremental plasticity. - Bruchmechanik, GKSS-Forschungszentrum, Geesthacht, Germany, Elsevier pp.127-209.

[20] O’Dowd N.P. (1995): Application of two parameter approaches in elastic-plastic fracture mechanics. Engineering Fracture Mechanics, vol.52, No.3, pp.445-465.

[21] PN-88/H-04336 "Test method for fracture toughness by determining the critical value of J-integral, $\mathrm{J}_{\mathrm{Ic}}$ ", Polish Committee for Standardization, Metrology and Quality, (1988) (in Polish).

[22] ASTM, 1983, ASTM E 399-83, Standard Test Method for Plane-Strain Fracture Toughness of Metallic Measurement.

[23] ASTM, 2005, ASTM E 1820-05 Standard Test Method for Measurement of Fracture Toughness, American Society for Testing and Materials.

[24] PN-EN 1993 Eurocode 3: Design of steel structures (in Polish)

[25] BS, 1991, BS 7448, Fracture Mechanics Toughness Tests. Method for determination KIC, critical CTOD and critical J values.

[26] ADINA 8.8, ADINA: User Interface Command Reference Manual-Volume I: ADINA Solids \& Structures Model Definition, Report ARD 11-2, ADINA R\&D, Inc., 2011.

[27] ADINA 8.8, ADINA: Theory and Modeling Guide - Volume I: ADINA Solids \& Structures, Report ARD 11-8, ADINA R\&D, Inc., 2011.

[28] Sherry A.H., Wilkes M.A., Beardsmore D.W. and Lidbury D.P.G. (2005): Material constraint parameters for the assessment of shallow defects in structural components - Part I: Parameter solutions. - Engineering Fracture Mechanics, vol.72, pp.2373-2395. 
[29] Sherry A.H., Hooton D.G., Beardsmore D.W. and Lidbury D.P.G. (2005): Material constraint parameters for the assessment of shallow defects in structural components - Part II: constraint - based assessment of shallow cracks. - Engineering Fracture Mechanics, vol.72, pp.2396-2415.

[30] Graba M. (2016): The hybrid method for determination of elastic-plastic fracture mechanics parameters for SEN(B) specimens. - In press.

[31] Table Curve 3D version 4.0.0, 1993-2002

[32] Sumpter J.D.G. and Forbes A.T. (1992): Constraint Based Analysis of Shallow Cracks in Mild Steel. TWI/EWI/IS International Conference on Shallow Crack Fracture Mechanics Test and Application, M.G. Dawes, Ed., Cambridge, UK, paper 7.

[33] Graba M. (2008): The influence of material properties on the Q-stress value near the crack tip for elastic-plastic materials. - Journal of Theoretical and Applied Mechanics, vol.46, No.2, pp.269-290, Warsaw 2008.

Received: June 1, 2016

Revised: July 13, 2016 